\title{
Anticorrosive efficiency of novel 1,4-benzothiazinone derivative for mild steel in phosphoric acid solution
}

\section{A. El-khlifi, ${ }^{1}$ M. Saadouni, ${ }^{2}$ R. Ijoub, ${ }^{1}$ Y. El Aoufir, ${ }^{3,4}$ S. Boukhriss, ${ }^{2}$ B. Hammouti ${ }^{*}$ and M. Ouhssine ${ }^{1} *$}

${ }^{1}$ Laboratoire de Biotechnologie, Environnement et Qualité, Faculté des Sciences, Université Ibn Tofaïl, 14000 Kénitra, Morocco

${ }^{2}$ Laboratory of Organic, Organometallic and Theoretical Chemistry, Faculty of Science, Ibn Tofail University, 14000 Kenitra, Morocco

${ }^{3}$ Laboratory of Separation Processes, Faculty of Sciences, University Ibn Tofail, Kénitra, Morocco

${ }^{4}$ Laboratory of Nanotechnology, Materials \& Environment, Faculty of Sciences, Mohammed V University, Rabat, Morocco

${ }^{5}$ Laboratory of Analytical Chemistry, Materials, and Environment (LC2AME), Faculty of Sciences, University of Mohammed Premier, B.P. 717, 60000 Oujda, Morocco

*E-mail: hammoutib@gmail.com, ouhssineunivit@gmail.com

\begin{abstract}
Corrosion is a big challenge and many corrosion control methods have been adopted all over the world. It can damage the materials, which are used to construct automobiles, pipeline systems, bridges and buildings, petroleum refineries, etc. Corrosion inhibitors are used as effective alternatives for the protection of metallic surfaces against corrosion. Herein, the corrosion inhibition characteristics of 2-(4-chlorophenyl)-1,4-benzothiazin-3-one (CBT) have been studied as efficient inhibitor for corrosion control of mild steel in $2.0 \mathrm{M}$ phosphoric acid solution using potentiodynamic polarization, weight loss measurements and electrochemical impedance spectroscopy (EIS) techniques. The effects of inhibitor concentration on the inhibition action were investigated. The corrosion inhibition efficiency increased with the increase of CBT concentration up to $85 \%$ obtained at $25^{\circ} \mathrm{C}$ at $5 \mathrm{mM}$ concentration. The adsorption of CBT on metal surface obeyed Langmuir adsorption isotherm. Adsorption isotherm study suggests that both physical and chemical adsorptions may be the type of adsorption of the inhibitor on the metal surface. Polarization measurements showed that the CBT acted as mixed inhibitor. The surface morphology of mild steel, in the absence and presence of CBT in $2.0 \mathrm{M}$ phosphoric acid solution, was studied using scanning electron microscopy (SEM). The SEM analysis strongly supports the results of electrochemical measurements.
\end{abstract}

Keywords: corrosion inhibition, benzothiazine, mild steel, phosphoric acid, EIS. 


\section{Introduction}

Metallic corrosion is attracting the attention of researchers. Researchers all over the world are searching for some methods to avoid corrosion damage. Using inhibitors is an effective method to reduce corrosion rate $[1,2]$.

An acid wash process is widely used in many industries in order to cleaning and descaling of steel substrates [3-5]. In acid pickling process, hydrochloric acid, phosphoric acid and sulfuric acid are used due to their special chemical properties [6]. By considering the fact that mentioned mineral acids are aggressive solution for metallic substrates, using corrosion inhibitors in acidic bath is one of the most practical methods for preventing the corrosion of metals. As a result, corrosion inhibitors for acidic media have attracted increasing attention due to their extended applications [7]. Up to now, little work $[8,9]$ appears to have been done on the inhibition of steel in $\mathrm{H}_{3} \mathrm{PO}_{4}$ solutions.

1,4-Benzothiazine is the pharmacophore of phenothiazines, which are well established anti-psychotic drugs [10], and is also known as the basic unit for their utility as dyestuffs [11], photographic developers, ultraviolet light absorbers and antioxidants [12]. Recently, the emergence of antibiotic-resistant bacterial strains has increased dramatically, so that the search for efficient substances to control micro-organisms is of paramount importance [13-16].

The present work is to investigate the corrosion inhibition of mild steel (MS) in $2.0 \mathrm{M}$ $\mathrm{H}_{3} \mathrm{PO}_{4}$ by 2-(4-chlorophenyl)-1,4-benzothiazin-3-one (CBT) using weight loss, potentiodynamic polarization methods, electrochemical impedance spectroscopy (EIS) and scanning electron microscopy (SEM).

\section{Experimental details}

\subsection{Synthesis}

General procedure for the preparation of 2-(4-chlorophenyl)-1,4-benzothiazin-3-one (CBT): To a solution of epoxide (1) $(5 \mathrm{mmol})$ in $\mathrm{MeCN}(20 \mathrm{~mL})$, are added the 2-aminothiophenol (2) $(5 \mathrm{mmol})$. The mixture is refluxed for $22 \mathrm{~h}$. The solvent was removed under reduced pressure and the residue obtained is added to a mixture of $\mathrm{Et}_{2} \mathrm{O}$ /petroleum ether, the 2-arylbenzothiazin-3-one precipitate slowly and are then purified by flash chromatography on alumina column eluted with acetone to give solids, which are recrystallized in EtOH.

2-(4-Chlorophenyl)-1,4-benzothiazin-3-one: (1.23 g, 90\%); $\mathrm{mp} 196-197^{\circ} \mathrm{C} \quad(\mathrm{mp}$ 198.5-199.5 [26]); IR (KBr): 3220, $\left.1660 \mathrm{~cm}^{-1} ;{ }^{1} \mathrm{H} \mathrm{NMR} \mathrm{(300} \mathrm{MHz,} \mathrm{CDCl}_{3}+\mathrm{CF}_{3} \mathrm{CO}_{2} \mathrm{H}\right) \delta$ 4.71 (s, 1H, CHS), 6.93-7.34 (m, 8H, Ar), 10.00 (s, 1H, NH); ${ }^{13} \mathrm{C}$ NMR (75 MHz, $\mathrm{CDCl}_{3}+$ $\left.\mathrm{CF}_{3} \mathrm{CO}_{2} \mathrm{H}\right) \delta 45.7,118.2,119.8,122.4,125.7,126.1,127.7,129.2,132.4,133.1,135.2$, 169.8; MS m/z (\%): 275 (M+, 1\%), 151 (100), 96 (78), 123 (73). 


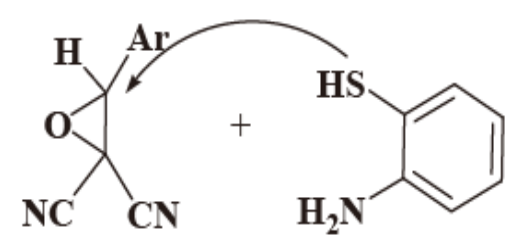

1

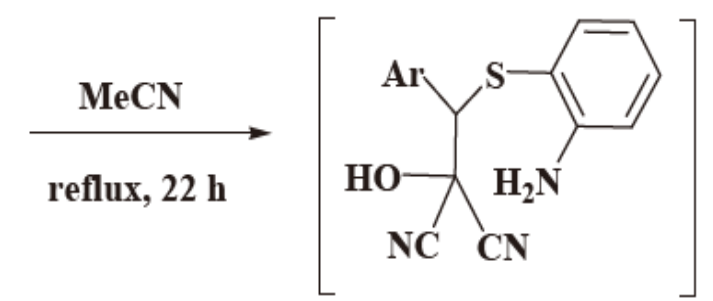

$[\mathbf{A}]$

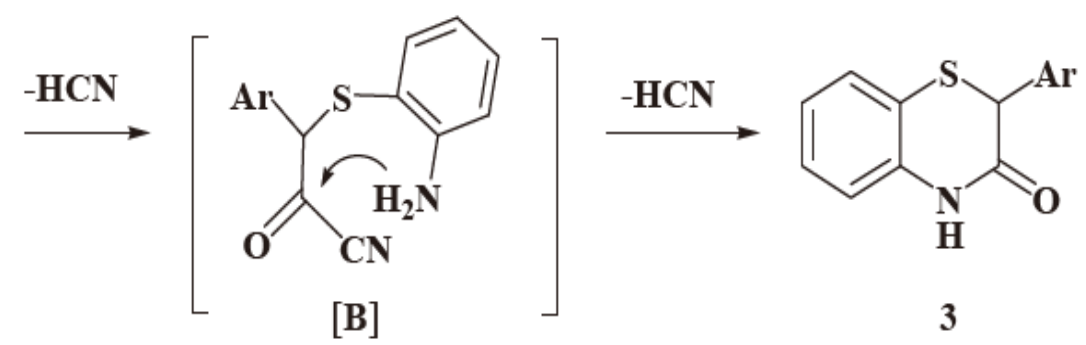

Scheme 1. Synthesis of the 1,4-benzothiazines-3-one 3.

\subsection{Electrodes, chemicals and test solution}

Corrosion tests have been performed, using the gravimetric and electrochemical measurements, on electrodes cut from sheets of mild steel with the chemical composition: $0.370 \% \mathrm{C}, 0.230 \% \mathrm{Si}, 0.680 \% \mathrm{Mn}, 0.016 \% \mathrm{~S}, 0.077 \% \mathrm{Cr}, 0.011 \% \mathrm{Ti}, 0.059 \% \mathrm{Ni}$, $0.009 \% \mathrm{Co}, 0.160 \% \mathrm{Cu}$, and the remainder iron. The aggressive medium of phosphoric acid used for all studies were prepared by dilution of analytical grade $85 \% \mathrm{H}_{3} \mathrm{PO}_{4}$ with double distilled water. The concentrations of $\mathrm{CBT}$ used in this investigates were varied from $10^{-4}$ to $5 \times 10^{-3} \mathrm{M}$.

\subsection{Gravimetric measurements}

Gravimetric measurements were realized in a double walled glass cell equipped with a thermostat-cooling condenser. The carbon steel specimens used have a rectangular form with dimension of $2.5 \times 2.0 \times 0.2 \mathrm{~cm}$ were abraded with a different grade of emery paper $(320,800,1200)$ and then washed thoroughly with distilled water and acetone. After weighing accurately, the specimens were immersed in beakers which contained $100 \mathrm{ml}$ acid solutions without and with various concentrations of CBT at temperature equal to $303 \mathrm{~K}$ remained by a water thermostat for $6 \mathrm{~h}$ as immersion time. The gravimetric tests were performed by triplicate at same conditions. The corrosion rates $\left(C_{R}\right)$ and the inhibition efficiency $\left(\eta_{w \mathrm{~m}}, \%\right)$ of mild steel have been evaluated from mass loss measurement using the following equations:

$$
\eta_{\mathrm{w}}=\frac{C_{R}-C_{R}^{\prime}}{C_{R}} \times 100
$$




$$
\theta=1-\frac{C_{R}^{\prime}}{C_{R}} \Rightarrow \theta=\frac{\left(\eta_{\mathrm{w}} \%\right)}{100}
$$

Where $C_{R}$ and $C_{R}^{\prime}$ are the corrosion rates of the mild steel in phosphoric acid without and with the studied range of the CBT concentrations, respectively, $\theta$ is the degree of surface coverage.

\subsection{Electrochemical measurements}

Electrochemical measurements, including stationary methods (PDP) and transient (EIS) were performed in a three-electrode cell. Pure mild steel specimen was used as the working electrode, a saturated calomel (SCE) as reference and an area platinum as counter electrode (CE) were used. All potentials were measured against SCE. The working electrode was immersed in a test solution for $30 \mathrm{~min}$ until the corrosion potential of the equilibrium state $\left(E_{\text {corr }}\right)$ was achieved using a type PGZ100 potentiostat. The potentiodynamic polarization curves were determined by a constant sweep rate of $1 \mathrm{mV} / \mathrm{s}$. The measurements of the transitory method (EIS) were determined, using ac signals of amplitude $10 \mathrm{mV}$ peak to peak at different conditions in the frequency range of $100 \mathrm{kHz}$ to $10 \mathrm{mHz}$. The data obtained by EIS method were analyzed and fitted using graphing and analyzing impedance software, version Zview2. For PDP method, the inhibition efficiency of the studied compound was calculated using the following equation:

$$
\eta_{\mathrm{PDP}}(\%)=\left[1-\frac{i_{\text {corr }}}{i_{\text {corr }}^{0}}\right] \times 100
$$

where $i_{\text {corr }}$ and $i_{\text {corr }}^{0}$ are the corrosion rates in the presence and absence of inhibitor, respectively. The impedance diagrams were determined by EIS method. To confirm reproductibility, all experiments were repeated three times and the evaluated inaccuracy does not exceed $10 \%$. For EIS method, the inhibition efficiency was calculated using the following equation:

$$
\eta_{\mathrm{EIS}}(\%)=\left[\frac{R_{\mathrm{p}(\mathrm{inh})}-R_{\mathrm{p}}}{R_{\mathrm{p}(\mathrm{inh})}}\right] \times 100
$$

where $R_{\mathrm{p}}$ and $R_{\mathrm{p}(\mathrm{inh})}$ were the polarisation resistance of mild steel electrode in the uninhibited and inhibited solutions, respectively.

\subsection{SEM}

The changes of the surface morphology of the mild steel in absence and in presence of the optimum concentration of CBT was studied using Scanning Electron Microscopy (SEM) after $6 \mathrm{~h}$ of immersion at $303 \mathrm{~K}$. SEM (Hitachi TM-1000) with an accelerating voltage of $15 \mathrm{kV}$ was used for the experiments. 


\section{Results and discussion}

\subsection{Polarization results}

The potentiodynamic polarization curves for mild steel in $2 \mathrm{M} \mathrm{H}_{3} \mathrm{PO}_{4}$ solution at $298 \mathrm{~K}$ with and without inhibitor are presented in Figure 2. The curves are shifted to lower current regions in the presence of inhibitor showing that the studied inhibitor inhibits the corrosion reaction. The associated electrochemical parameters such as corrosion potential $\left(E_{\text {corr }}\right)$, corrosion current density $\left(i_{\text {corr }}\right)$, anodic and cathodic Tafel slopes $\left(\beta_{\mathrm{a}}\right.$ and $\left.\beta_{\mathrm{c}}\right)$ were obtained from the intersection of anodic and cathodic Tafel lines, and corrosion inhibition efficiencies $\eta_{\mathrm{PDP}}(\%)$ were calculated and presented in Table 1.

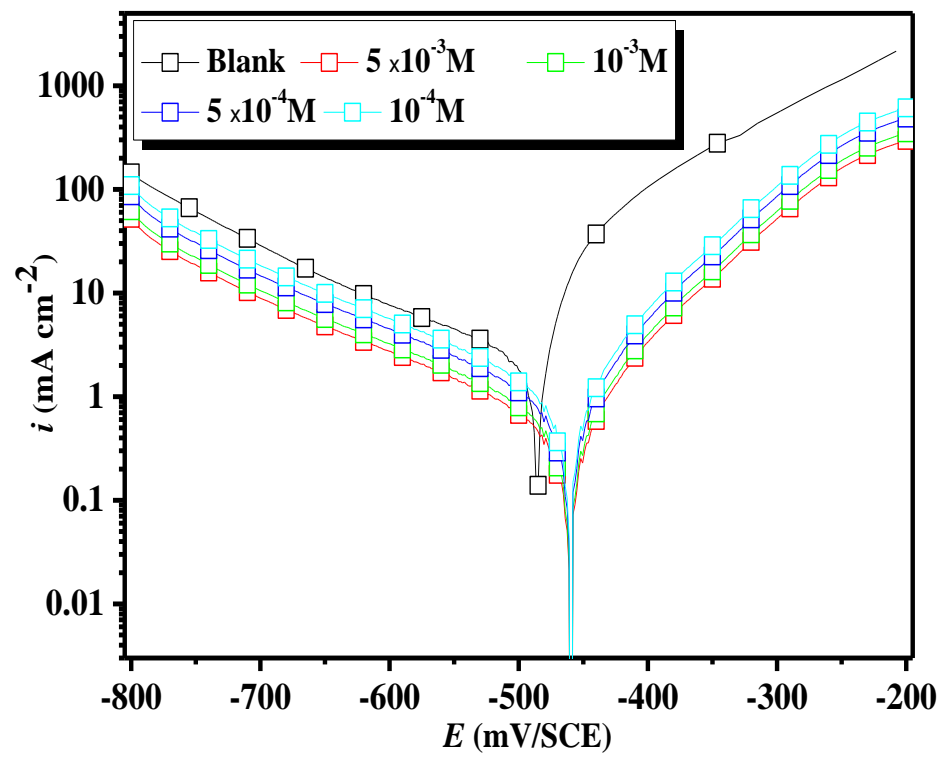

Figure 2. Potentiodynamic polarization curves for mild steel in $2 \mathrm{M} \mathrm{H}_{3} \mathrm{PO}_{4}$ solution in the presence and absence of different concentrations of CBT at $298 \mathrm{~K}$.

Table 1. The electrochemical parameters calculated by the PDP technique for the corrosion of mild steel in $2 \mathrm{M} \mathrm{H}_{3} \mathrm{PO}_{4}$ in the absence and presence of different concentrations of CBT at $298 \mathrm{~K}$.

\begin{tabular}{ccccccc}
\hline Inhibitor & $\begin{array}{c}\text { Concentration } \\
(\mathbf{M})\end{array}$ & $\begin{array}{c}-\boldsymbol{E}_{\text {corr }} \\
(\mathbf{m V} / \mathbf{S C E})\end{array}$ & $\begin{array}{c}-\boldsymbol{\beta}_{\mathbf{c}} \\
(\mathbf{m V} / \mathbf{d e c})\end{array}$ & $\begin{array}{c}\boldsymbol{\beta}_{\mathbf{a}} \\
(\mathbf{m V} / \mathbf{d e c})\end{array}$ & $\begin{array}{c}\boldsymbol{i}_{\text {corr }} \\
(\boldsymbol{\mu} \mathbf{A} / \mathbf{c m})\end{array}$ & $\begin{array}{c}\boldsymbol{\eta}_{\mathbf{P D P}} \\
(\boldsymbol{\%})\end{array}$ \\
\hline $\mathrm{H}_{3} \mathrm{PO}_{4}$ & 2 & 488 & 135 & 92 & 2718 & - \\
\hline \multirow{3}{*}{$\mathrm{CBT}$} & $5 \times 10^{-3}$ & 463 & 133 & 76 & 504 & 81 \\
& $10^{-3}$ & 465 & 131 & 74 & 631 & 76 \\
& $5 \times 10^{-4}$ & 461 & 137 & 77 & 856 & 68 \\
& $10^{-4}$ & 464 & 139 & 74 & 1043 & 61 \\
\hline
\end{tabular}


It is clear that the addition of inhibitor hindered the acid attack on the steel electrode and a comparison of curves in both cases, showed that, with respect to the blank, increasing the concentration of the inhibitor gave rise to a consistent decrease in anodic and cathodic current densities indicating that inhibitor acts as mixed type inhibitor $[17,18]$. Increasing of inhibitor concentration results a reduction in the corrosion current densities and an increase in $\eta \%$, which suggests that the protective film adsorbed on the metal surface tends to be more complete at higher inhibitor concentrations. It is clear from Table 1 that after increasing the concentration of inhibitor, the inhibition efficiency increased, while the corrosion current density decreased due to adsorption of inhibitor molecule on the metal surface. The minor shift in $E_{\text {corr }}$ value towards positive direction in the presence of inhibitor as compared to the $E_{\text {corr }}$ value in the absence of inhibitor indicates that tested inhibitor acts as mixed type inhibitor [19].

\subsection{Electrochemical impedance spectroscopy (EIS)}

Figure 3 shows the Nyquist diagrams for mild steel in $2 \mathrm{M} \mathrm{H}_{3} \mathrm{PO}_{4}$ at $298 \mathrm{~K}$ containing various concentrations of CBT. Inspection of Figure 3 reveals that the addition of the inhibitor increases the capacitive loop diameter without affecting their characteristic features. This indicates the strengthening of the formed inhibitive film, which is responsible for the inhibition action of this inhibitor. The protective film is formed because of adsorption of inhibitor molecules on the mild steel surface without changing the mechanism of corrosion process. It can be seen clearly from Figure 3, that the Nyquist plots show a single capacitive semicircle shape at higher frequencies in the presence of inhibitor. This indicates that corrosion of mild steel in $2 \mathrm{M} \mathrm{H}_{3} \mathrm{PO}_{4}$ solution is mainly controlled by charge transfer process [20-22].

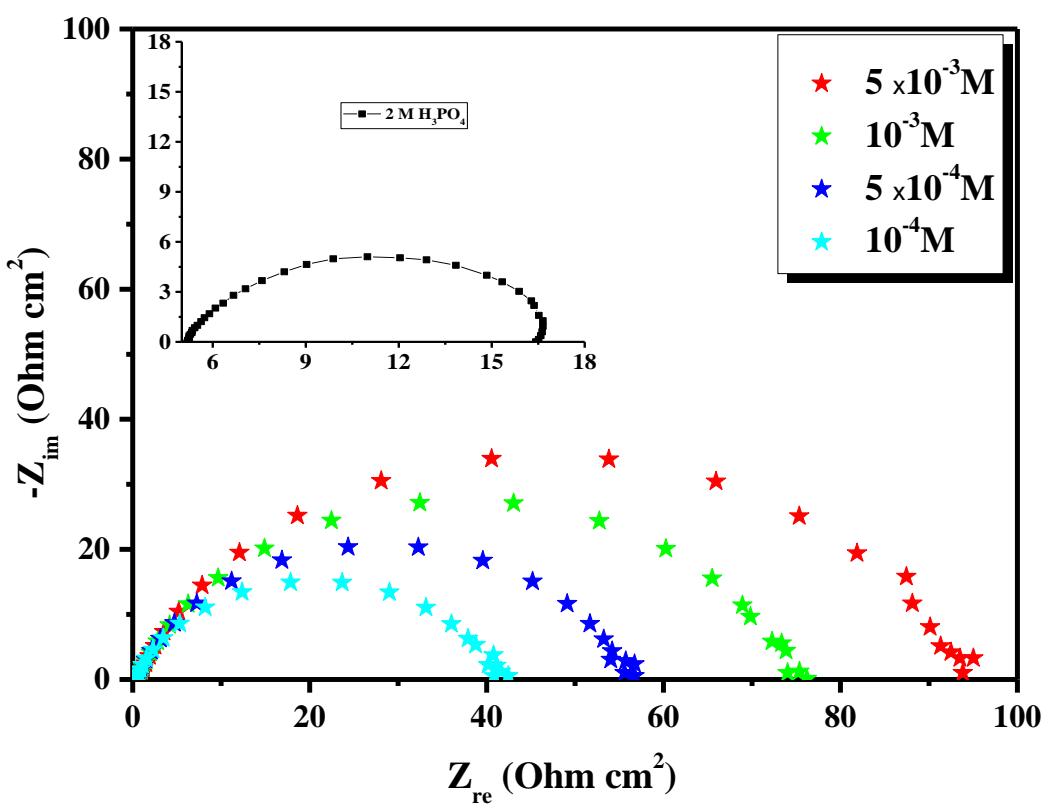

Figure 2. Nyquist plots for carbon steel in $2 \mathrm{M} \mathrm{H}_{3} \mathrm{PO}_{4}$ solution containing various concentrations of CBT at $298 \mathrm{~K}$. 
The impedance spectra were fitted to the $R_{\mathrm{S}}\left(R_{\mathrm{p}} \mathrm{CPE}\right)$ equivalent circuit of the form in Figure 3. It consists of an electrolyte resistance $\left(R_{\mathrm{s}}\right)$, a polarization resistance $\left(R_{\mathrm{p}}\right)$ and a constant phase element (CPE), which is used for a non-ideal double layer. The impedance of this element is frequency-dependent and can be calculated using the Equation 5:

$$
Z_{\mathrm{CPE}}=\frac{1}{Q(\mathrm{j} \omega)^{n}}
$$

Where $Q$ is the $C P E$ constant (in $\Omega^{-1} \cdot \mathrm{S}^{n} \cdot \mathrm{cm}^{-2}$ ), $\omega$ is the angular frequency (in $\mathrm{rad} \cdot \mathrm{s}^{-1}$ ), $\mathrm{j}^{2}=-1$ is the imaginary number and $n$ is a CPE exponent which can be used as a gauge for the heterogeneity or roughness of the surface $[23,24]$.

The electrochemical kinetic parameters obtained from the fitting of impedance spectra are listed in Table 2. The impedance value at low frequency region corresponds to the polarization resistance $\left(R_{\mathrm{p}}\right)$. The $R_{\mathrm{p}}$ values for the inhibited systems are generally higher than that of the uninhibited $2 \mathrm{M} \mathrm{H}_{3} \mathrm{PO}_{4}$ system, which implies that the studied inhibitor inhibits mild steel corrosion in $2 \mathrm{M} \mathrm{H}_{3} \mathrm{PO}_{4}$. The increased $R_{\mathrm{p}}$ values with increasing the concentration of the inhibitor correspond to an enhanced impedance to electrochemical corrosion at high inhibitor concentration. In addition, the double layer capacitances, $C_{\mathrm{d}}$, for a circuit including a $C P E$ were calculated by using the following Equation 6:

$$
C_{\mathrm{dl}}=\sqrt[n]{Q \times R_{\mathrm{p}}^{1-n}}
$$

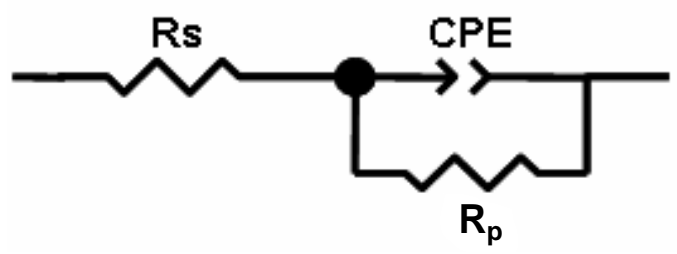

Figure 3. Equivalent electrical circuit.

Table 2. Impedance parameters recorded for mild steel electrode in $2 \mathrm{M} \mathrm{H}_{3} \mathrm{PO}_{4}$ solution in the absence and presence of different concentrations of inhibitor at $298 \mathrm{~K}$.

\begin{tabular}{ccccccc}
\hline Inhibitor & $\begin{array}{c}\text { Concentration } \\
(\mathbf{M})\end{array}$ & $\begin{array}{c}\mathbf{R}_{\mathbf{p}} \\
\left(\boldsymbol{\Omega} \cdot \mathbf{c m}^{\mathbf{2}}\right)\end{array}$ & $\begin{array}{c}\mathbf{Y}_{\mathbf{0}} \times \mathbf{1 0}^{-4} \\
\left(\mathbf{s n} \cdot \mathbf{\Omega}^{-\mathbf{1}} \cdot \mathbf{c m}^{-\mathbf{2}}\right)\end{array}$ & $\boldsymbol{n}$ & $\begin{array}{c}\boldsymbol{C}_{\mathbf{d l}} \\
\left(\boldsymbol{\mu} \mathbf{F} / \mathbf{c m}^{\mathbf{2}}\right)\end{array}$ & $\begin{array}{c}\eta_{\text {EIS }} \\
(\boldsymbol{\%})\end{array}$ \\
\hline Blank & 2.0 & 14 & 2.1024 & 0.88 & 94.96 & - \\
\hline \multirow{3}{*}{ CBT } & $5 \times 10^{-3}$ & 93 & 0.6108 & 0.88 & 30 & 85 \\
& $10^{-3}$ & 73 & 0.8441 & 0.85 & 34 & 81 \\
& $5 \times 10^{-4}$ & 55 & 1.0017 & 0.87 & 46 & 74 \\
& $10^{-4}$ & 41 & 1.3784 & 0.84 & 51 & 66 \\
\hline
\end{tabular}


The calculated $C_{\mathrm{dl}}$ values in the presence of inhibitor are generally lower than that of the $2 \mathrm{M} \mathrm{H}_{3} \mathrm{PO}_{4}$ without inhibitor. This implies that the inhibitor forms protective film on the steel surface. The $C_{\mathrm{dl}}$ values also decrease with increasing concentration for the inhibitor, this implies that the thickness of the protective film increases with increasing inhibitor concentration [25]. The $\eta_{\text {EIS }}$ values are high for the studied inhibitor indicating that it is good corrosion inhibitor for mild steel in $2 \mathrm{M} \mathrm{H}_{3} \mathrm{PO}_{4}$.

\subsection{Weight loss study}

Effect of inhibitor (CBT) concentration on the corrosion of mild steel in $2.0 \mathrm{M} \mathrm{H}_{3} \mathrm{PO}_{4}$ was studied by weight loss measurement at $298 \mathrm{~K}$ and the results are given in Table 3 . The data in Table 3 reveal that as the concentration of CBT increases inhibition efficiency increases and corrosion rate decreases. This behavior can be attributed to the increase in surface area covered by the adsorbed molecules on the mild steel surface with an increase in the concentration of CBT. The maximum efficiency of $80 \%$ was achieved at the concentration of $5 \times 10^{-3} \mathrm{M}$.

Table 3. Effect of CBT concentration on corrosion data of mild steel in $2.0 \mathrm{M} \mathrm{H}_{3} \mathrm{PO}_{4}$

\begin{tabular}{ccccc}
\hline Inhibitor & $\begin{array}{c}\text { Concentration } \\
(\mathbf{M})\end{array}$ & $\begin{array}{c}\boldsymbol{C}_{\mathbf{R}} \\
\left(\mathbf{m g} \cdot \mathbf{c m}^{-2} \cdot \mathbf{h}^{-\mathbf{1}}\right)\end{array}$ & $\begin{array}{c}\boldsymbol{\eta}_{\mathbf{w}} \\
(\boldsymbol{\%})\end{array}$ & $\boldsymbol{\theta}$ \\
\hline Blank & 2.0 & 5.061 & - & - \\
\hline \multirow{2}{*}{ CBT } & $5 \times 10^{-3}$ & 1.045 & 80 & 0.80 \\
& $10^{-3}$ & 1.118 & 78 & 0.78 \\
& $5 \times 10^{-4}$ & 1.441 & 71 & 0.71 \\
& $10^{-4}$ & 1.654 & 67 & 0.67 \\
\hline
\end{tabular}

\subsection{Adsorption isotherm}

As a rule, inhibition of corrosion of steel in acidic solutions by inhibitors can be explained on the basis of molecular adsorption [4,26-28]. Thus, the application of adsorption isotherm is very useful to study the mechanism of corrosion inhibition. To find a suitable adsorption isotherm in the present study, several commonly used isotherms were tested, among which the Langmuir adsorption isotherm was found to fit well with our experimental data. The Langmuir isotherm can be represented as [29]:

$$
\frac{C_{\mathrm{inh}}}{\theta}=\frac{1}{K_{\mathrm{ads}}}+C_{\mathrm{inh}}
$$

where $C_{\text {inh }}$ is the concentration, $K_{\text {ads }}$ is the equilibrium constant of the adsorption process. $K_{\text {ads }}$ are related to the standard free energy of adsorption $\Delta G_{\text {ads }}^{0}$ by the following equation [30]: 


$$
\Delta G_{\mathrm{ads}}^{0}=-R T \ln \left(K_{\mathrm{ads}} \times 55.5\right)
$$

where $R$ represents the gas constant and $T$ is the absolute temperature. The value of 55.5 is the concentration of water in solution in $\mathrm{mol} / \mathrm{L}$.

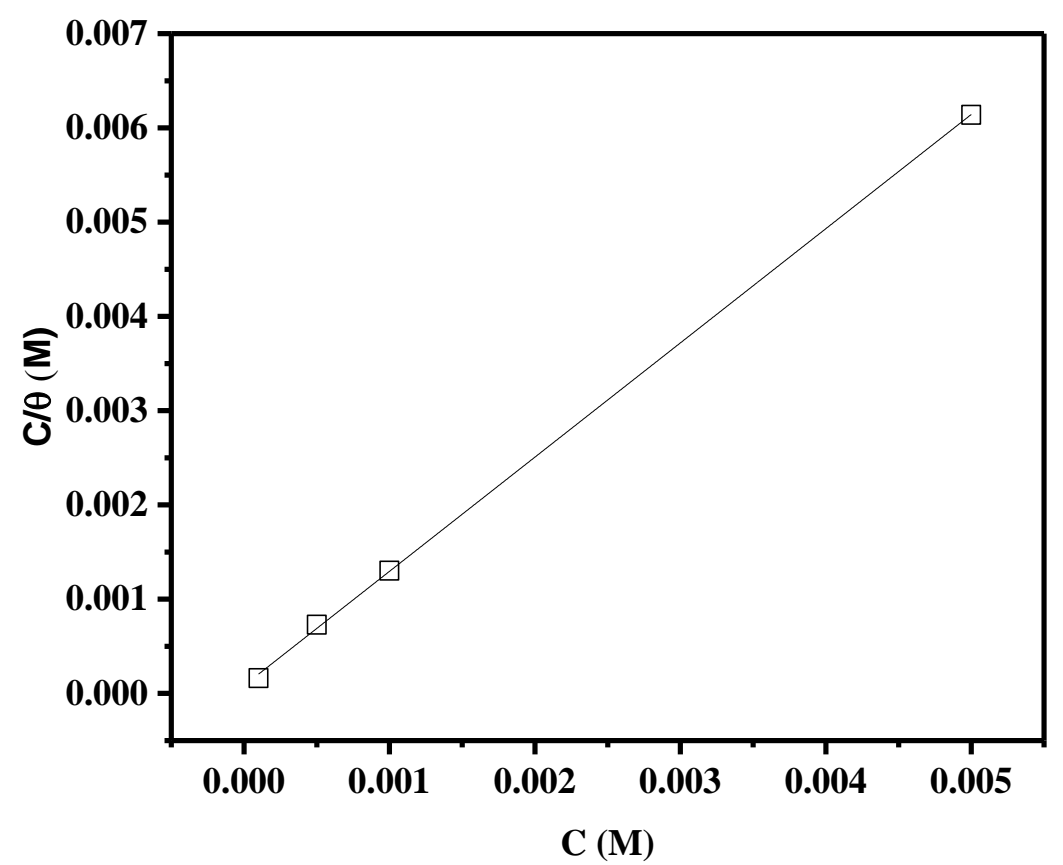

Figure 4. Langmuir adsorption of inhibitor on the mild steel surface in $2 \mathrm{M}_{3} \mathrm{PO}_{4}$ solution at $298 \mathrm{~K}$.

The value of $\Delta G_{\mathrm{ads}}^{0}$ determined is $-37 \mathrm{~kJ} \cdot \mathrm{mol}^{-1}(K=11951)$ revealing that both physisorption and chemisorption processes were involved in the adsorption process of benzothiazinone derivative on mild steel surface [31-33].

\subsection{Surface characterization}

The SEM micrographs of mild steel surfaces in absence and presence of optimum concentration of CBT after 6h immersion time are shown in Figure 5. Figure 5(b) depicts the SEM micrograph of mild steel surface in free acid solution, which revealed a very rough surface with characteristic pits and cracks along with strongly damaged surface compared to polished surface (Figure 5(a)). Figure 5(c) shows the surface morphology of mild steel specimen immersed in $2.0 \mathrm{M} \mathrm{H}_{3} \mathrm{PO}_{4}$ containing maximum concentration of CBT. Inspection of the Figure 5(c) revealed that mild steel surface morphology remarkably improved in presence of CBT with comparatively smooth and less corroded surface which might be attributed to the formation of protective film by CBT on metal surface. 

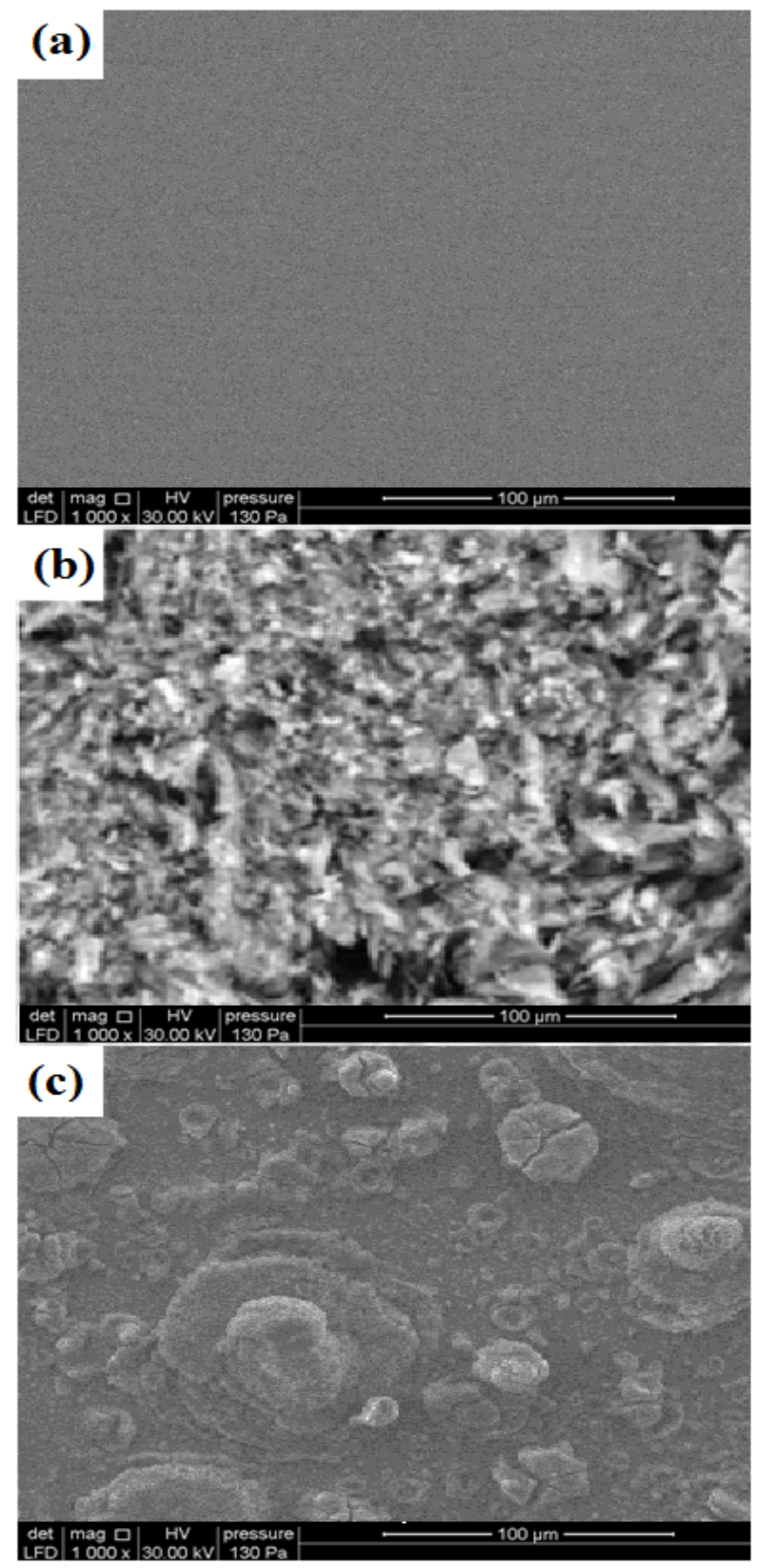

Figure 5. The SEM micrographs in polished steel (a) in absence (b) and presence (c) of CBT at $5 \times 10^{-3}$.

\section{Conclusion}

The studied inhibitor shows excellent inhibition properties for corrosion of mild steel in $2.0 \mathrm{M} \mathrm{H}_{3} \mathrm{PO}_{4}$ and its inhibition efficiency increases with increasing the concentration. The results obtained from weight loss measurements, polarization curves and electrochemical 
impedance study (EIS) are in reasonable agreement. The adsorption of the inhibitor obeys Langmuir adsorption isotherm. The result of polarization measurement demonstrated that the inhibitor under investigation is mixed type.

\section{Acknowledgements}

We wish to thank Dr. Hassane Lgaz, Konkuk University, South Korea for his precious help in conducting this study.

\section{References}

1. M. Filali, E.M. El Hadrami, A. Ben-Tama, B. Hafez, I. Abdel-Rahman, A. Harrach, H. Elmsellem, B. Hammouti, M. Mokhtari, S.E. Stiriba and M. Julve, 3,6-di(Pyridin-2yl) pyridazine derivatives as original and new corrosion inhibitors in support of mild steel: Experimental studies and DFT investigational, Int. J. Corros. Scale Inhib., 2019, 8, no. 1, 93-109. doi: 10.17675/2305-6894-2019-8-1-9

2. S. Hadisaputra, A.A. Purwoko, I. Ilhamsyah, S. Hamdiani, D. Suhendra, N. Nuryono and B. Bundjali, A combined experimental and theoretical study of (E)-ethyl 3-(4methoxyphenyl)acrylate as corrosion inhibitor of iron in $1 \mathrm{M} \mathrm{HCl}$ solutions, Int. J. Corros. Scale Inhib., 2018, 7, no. 4, 633-647. doi: 10.17675/2305-6894-2018-7-4-10

3. S.A. Mrani, S.E. El Arrouji, K. Karrouchi, F. El Hajjaji, K.I. Alaoui, Z. Rais and M. Taleb, Inhibitory performance of some pyrazole derivatives against corrosion of mild steel in 1.0 M HCl: Electrochemical, MEB and theoretical studies, Int. J. Corros. Scale Inhib., 2018, 7, no. 4, 542-569. doi: 10.17675/2305-6894-2018-7-4-5

4. Y.G. Avdeev, Nitrogen-containing six-membered heterocyclic compounds as corrosion inhibitors for metals in solutions of mineral acids - A review, Int. J. Corros. Scale Inhib., 2018, 7, no. 4, 460-497. doi: 10.17675/2305-6894-2018-7-4-1

5. S. Bouazama, J. Costat, J.M. Desjobertb, A. Benali, A. Guenbour and M. Tabyaoui, Influence of Lavandula Dentata essential oil on the corrosion inhibition of carbon steel in $1 \mathrm{M} \mathrm{HCl}$ solution, Int. J. Corros. Scale Inhib., 2019, 8, no. 1, 25-41. doi: 10.17675/2305-6894-2019-8-1-3

6. L. Tang, X. Li, G. Mu, L. Li and G. Liu, Synergistic effect between 4-(2-pyridylazo) resorcin and chloride ion on the corrosion of cold rolled steel in $1.0 \mathrm{M}$ phosphoric acid, Appl. Surf. Sci., 2006, 253, 2367-2372. doi: 10.1016/j.apsusc.2005.04.059

7. A. Singh, K.R. Ansari, J. Haque, P. Dohare, H. Lgaz, R. Salghi and M.A. Quraishi, Effect of electron donating functional groups on corrosion inhibition of mild steel in hydrochloric acid: Experimental and quantum chemical study, J. Taiwan Inst. Chem. Eng., 2018, 82, 233-251. doi: 10.1016/j.jtice.2017.09.021

8. M.E. Belghiti, A. Nahlé, A. Ansari, Y. Karzazi, S. Tighadouini, Y. El Ouadi, A. Dafali, B. Hammouti and S. Radi, Inhibition effect of $E$ and $Z$ conformations of 2pyridinealdazine on mild steel corrosion in phosphoric acid, Anti-Corros. Methods Mater., 2017, 64, 23-35. doi: 10.1108/ACMM-11-2015-1594 
9. M.S. Uwineza, M. Essahli and A. Lamiri, Corrosion inhibition of aluminium in $2 \mathrm{M}$ phosphoric acid using the essential oil of mentha pulegium leaves, Port. Electrochim. Acta., 2016, 34, 53-62. doi: 10.4152/pea.201601053

10. J. Barker and M. Miller, A double blind comparative trial of pericyazine and thioridazine in chronic schizophrenia, Br. J. Psychiatry, 1969, 115, 169-172.

11. R. Tanaka, K. Teramura and S. Yokoyama, Jap. Pat., 1966, 5833, Chem. Abstr., 1966, 40, 9062.

12. V.V. Dabholkar and R.P. Gavande, Synthesis and biological evaluation of oxadiazolyl1,4-benzothiazines, Rasayan J. Chem., 2010, 3, 655-659.

13. S. Alavi, M.H. Mosslemin, R. Mohebat and A.R. Massah, Green synthesis of novel quinoxaline sulfonamides with antibacterial activity, Res. Chem. Intermed., 2017, 43, 4549-4559. doi: 10.1007/s11164-017-2895-6

14. S.A. Shintre, D. Ramjugernath, M.S. Islam, R. Mopuri, C. Mocktar and N.A. Koorbanally, Synthesis, in vitro antimicrobial, antioxidant, and antidiabetic activities of thiazolidine-quinoxaline derivatives with amino acid side chains, Med. Chem. Res., 2017, 26, 2141-2151. doi: 10.1007/s00044-017-1922-X

15. G.R. Kamala and A.K. Velagaleti, Synthsis, characterisation and anti microbial evaluation of novel 2-substituted quinoxaline derivatives, Indian Drugs, 2017, 54, $5-10$.

16. G.-Y. Cheng, X. Wang, Y.-H. Pan, M.-H. Dai, H.-H. Hao and Z.-H. Yuan, The antimicrobial activities of quinoxaline 1,4-di-N-oxides, Chin. J. New Drugs, 2017, 26, 179-186.

17. H. Lgaz, K. Subrahmanya Bhat, R. Salghi, Shubhalaxmi, S. Jodeh, M. Algarra, B. Hammouti, I.H. Ali and A. Essamri, Insights into corrosion inhibition behavior of three chalcone derivatives for mild steel in hydrochloric acid solution, J. Mol. Liq., 2017, 238, 71-83. doi: 10.1016/j.molliq.2017.04.124

18. V. Srivastava, J. Haque, C. Verma, P. Singh, H. Lgaz, R. Salghi and M.A. Quraishi, Amino acid based imidazolium zwitterions as novel and green corrosion inhibitors for mild steel: Experimental, DFT and MD studies, J. Mol. Liq., 2017, 244, 340-352. doi: $10.1016 /$ j.molliq.2017.08.049

19. N. Saini, R. Kumar, H. Lgaz, R. Salghi, I.-M. Chung, S. Kumar and S. Lata, Minified dose of urispas drug as better corrosion constraint for soft steel in sulphuric acid solution, J. Mol. Liq., 2018, 269, 371-380. doi: 10.1016/j.molliq.2018.08.070

20. R. Aslam, M. Mobin, J. Aslam and H. Lgaz, Sugar based N,N'-didodecylN,N'digluconamideethylenediamine gemini surfactant as corrosion inhibitor for mild steel in 3.5\% NaCl solution-effect of synergistic KI additive, Sci. Rep., 2018, 8, 3690. doi: $10.1038 / \mathrm{s} 41598-018-21175-6$

21. A. Singh, K.R. Ansari, M.A. Quraishi, H. Lgaz and Y. Lin, Synthesis and investigation of pyran derivatives as acidizing corrosion inhibitors for N80 steel in hydrochloric acid: Theoretical and experimental approaches, J. Alloys Compd., 2018, 762, 347-362. doi: $10.1016 / j . j a l l c o m .2018 .05 .236$ 
22. A. Mishra, C. Verma, H. Lgaz, V. Srivastava, M.A. Quraishi and E.E. Ebenso, Synthesis, characterization and corrosion inhibition studies of N-phenyl-benzamides on the acidic corrosion of mild steel: Experimental and computational studies, J. Mol. Liq., 2018, 251, 317-332. doi: 10.1016/j.molliq.2017.12.011

23. M.A. Amin, M. Ahmed, H. Arida, T. Arslan, M. Saracoglu and F. Kandemirli, Monitoring corrosion and corrosion control of iron in $\mathrm{HCl}$ by non-ionic surfactants of the TRITON-X series-Part II. Temperature effect, activation energies and thermodynamics of adsorption, Corros. Sci., 2011, 53, 540-548. doi: 10.1016/j.corsci.2010.09.019

24. M.A. Amin, S.A. El-Rehim, E. El-Sherbini and R.S. Bayoumi, Chemical and electrochemical (AC and DC) studies on the corrosion inhibition of low carbon steel in $1.0 \mathrm{M} \mathrm{HCl}$ solution by succinic acid-temperature effect, activation energies and thermodynamics of adsorption, Int. J. Electrochem. Sci., 2008, 3, 199-215.

25. K. Khaled, Molecular simulation, quantum chemical calculations and electrochemical studies for inhibition of mild steel by triazoles, Electrochim. Acta, 2008, 53, 3484-3492. doi: 10.1016/j.electacta.2007.12.030

26. R. Hameed and A. Shamroukh, Synthesis, characterization, and evaluation of some acyclic S-nucleosides of pyrazolo [3,4-d] pyrimidine-thiones as corrosion inhibitors for carbon steel in hydrochloric acid, Int. J. Corros. Scale Inhib., 2017, 6, no. 3, 333-348. doi: $10.17675 / 2305-6894-2017-6-3-8$

27. A. Peter and S. Sharma, Use of Azadirachta indica (AZI) as green corrosion inhibitor against mild steel in acidic medium: anti-corrosive efficacy and adsorptive behaviour, Int. J. Corros. Scale Inhib., 2017, 6, no. 2, 112-131. doi: 10.17675/2305-6894-2017-62-2

28. A. Berezhnaya, G.A. Shayea and V. Chernyavina, Mixtures of substituted pyridinium perchlorates with sulfur-containing organic compounds as inhibitors of acid corrosion of steel, Int. J. Corros. Scale Inhib., 2017, 6, no. 4, 372-383. doi: 10.17675/23056894-2017-6-4-2

29. D.S. Chauhan, K.R. Ansari, A.A. Sorour, M.A. Quraishi, H. Lgaz and R. Salghi, Thiosemicarbazide and thiocarbohydrazide functionalized chitosan as ecofriendly corrosion inhibitors for carbon steel in hydrochloric acid solution, Int. J. Biol. Macromol., 2018, 107, 1747-1757. doi: 10.1016/j.ijbiomac.2017.10.050

30. P. Dohare, D.S. Chauhan and M.A. Quraishi, Expired podocip drug as potential corrosion inhibitor for carbon steel in acid chloride solution, Int. J. Corros. Scale Inhib., 2018, 7, no. 1, 25-37. doi: 10.17675/2305-6894-2018-7-1-3

31. A. Chaouiki, H. Lgaz, I.-M. Chung, I.H. Ali, S.L. Gaonkar, K.S. Bhat, R. Salghi, H. Oudda and M.I. Khan, Understanding corrosion inhibition of mild steel in acid medium by new benzonitriles: Insights from experimental and computational studies, J. Mol. Liq., 2018, 266, 603-616. doi: 10.1016/j.molliq.2018.06.103 
32. H. Jafari, F. Mohsenifar and K. Sayin, A Study of New benzo[d]thiazol Derivatives as Corrosion Inhibitors for Steel AISI 1035 in Acidic Medium, Mor. J. Chem., 2019, 7, 37-48.

33. J. Haque, V. Srivastava, C. Verma, H. Lgaz, R. Salghi and M.A. Quraishi, N-Methyl$\mathrm{N}, \mathrm{N}, \mathrm{N}$-trioctylammonium chloride as a novel and green corrosion inhibitor for mild steel in an acid chloride medium: Electrochemical, DFT and MD studies, New J. Chem., 2017, 41, 13647-13662. doi: 10.1039/c7nj02254a 